\title{
Os tensionamentos no ensino sob o regime do capitalismo acadêmico na nova economia: 0 caso das universidades comunitárias regionais
}

\author{
The tensions in teaching under the academic capitalism regime in the new \\ economy: the case of regional community universities \\ Las tensiones en la enseñanza bajo el régimen del capitalismo académico en la \\ nueva economía: el caso de las universidades comunitarias regionales
}

CRISTINA FIOREZE

\begin{abstract}
Resumo: $\mathrm{O}$ artigo analisa as perspectivas e valores que orientam o ensino nas universidades, em um contexto de tensionamento mercantil. Metodologicamente, a pesquisa é desenvolvida junto às universidades comunitárias regionais do Rio Grande do Sul, por meio de análise documental e entrevistas com doze gestores e pesquisadores. Como resultados, identifica-se um movimento de deslocamento das instituições na direção do chamado capitalismo acadêmico na nova economia. Esta tendência, porém, coexiste com uma postura de resistência no sentido da preservação dos valores da educação superior como bem público.
\end{abstract}

Palavras-chave: Universidade; Ensino; Capitalismo Acadêmico; Bem Público; Modelo Comunitário.

\begin{abstract}
The article analyzes the perspectives and values that guide the teaching in universities in a context of market tension. Methodologically, the research is developed together with regional community universities in Rio Grande do Sul, throughout documental analysis and interviews with twelve gestors and researchers. As results, we identify an institutional displacement towards the socalled academic capitalism in the new economy. However, such tendency coexists with a resistance posture towards the preservation of the values of higher education as a public good.
\end{abstract}

Keywords: University; Teaching; Academic Capitalism; Public Good; Community Model.

Resumen: El artículo analiza las perspectivas y valores que orientan la enseñanza en las universidades, en un contexto de tensión mercantil. Metodológicamente, la investigación es desarrollada junto a las universidades comunitarias regionales de Rio Grande do Sul, por medio de análisis documental y entrevistas con doce gestores e investigadores. Como resultados, se identifica un movimiento de 
desplazamiento de las instituciones hacia el llamado capitalismo académico en la nueva economía. Esta tendencia, sin embargo, coexiste con una postura de resistencia en el sentido de la preservación de los valores de la educación superior como bien público.

Palabras clave: Universidad; Eseñanza; Capitalismo Académico; Bien público; Modelo Comunitario.

\section{INTRODUÇÃO}

O debate em torno da educação superior tem se intensificado desde o início deste século. Na chamada sociedade da informação (CASTELLS, 1999), o conhecimento é tomado como matéria-prima para o desenvolvimento econômico e, nesse sentido, crescem as críticas à universidade enquanto torre de marfim e advoga-se pela sua vinculação com o setor produtivo e o mercado. $\mathrm{Na}$ mesma toada, presencia-se o estímulo, por parte dos poderes públicos, para a aproximação das universidades com a tríade ciência, tecnologia e inovação. Nesses movimentos, pode-se destacar a influência de acordos como a Declaração de Bolonha, do final dos anos 1990, que, reconhecendo a centralidade do conhecimento para as sociedades, buscou promover adaptações na educação superior europeia de modo a incentivar o ingresso no mercado de trabalho, a competitividade e a mobilidade discente, produzindo com isso uma nova postura por parte das universidades. É dentro desse contexto mais amplo que se vê emergir a configuração do que Slaughter e Rhoades (2004) denominam de "capitalismo acadêmico na nova economia".

$\mathrm{Na}$ mesma esteira, a ampliação do acesso à educação superior, nível de ensino historicamente elitizado, passa a integrar a agenda mundial. Daí surge um conjunto de orientações de organismos internacionais que apontam para o mercado como solução para ampliação do acesso (CASTRO; ARAÚJO, 2018). Nessa perspectiva, é digno de nota o documento do Banco Mundial publicado em 1998, em que expõe seu entendimento de educação superior como bem privado (WORLD BANK, 1998).

O caso brasileiro é exemplar neste sentido, pois a expansão das taxas de atendimento observada no país - que deu um salto de aproximadamente um milhão e oitocentas matrículas em 1995 para mais de oito milhões em 2015 (BRASIL/ INEP, 2016) - é em grande medida decorrente da entrada das instituições de educação superior (IES) mercantis, o que se deu a partir dos anos 2000, quando essas novas instituições passaram a dividir espaço, dentro do setor privado, com as universidades privadas tradicionais, como as confessionais, especialmente as PUCs, e as comunitárias. Neste sentido os dados mostram que, em 2015, 24\% dos estudantes do ensino superior brasileiro estavam matriculados nas instituições 
públicas e 76\% em IES privadas (BRASIL/INEP, 2016). E, já em 2014, uma em cada quatro matrículas do ensino superior brasileiro estavam dentro dos oito maiores grupos educacionais mercantis, tais como Kroton, Estácio e Laureate (TOLEDO, 2016).

Embora se reconheça que as universidades brasileiras estão estruturadas em torno da indissociabilidade entre ensino, pesquisa e extensão, conforme preconizado pela Constituição Federal (BRASIL, 1988), observa-se que o novo contexto de transformações da educação superior apresenta nuances distintas em cada uma dessas três dimensões. Daí a relevância de se desenvolver análises voltadas para as particularidades. Assim, olhando mais especificamente para a dimensão do ensino e o que ocorre com ela dentro da lógica da educação como bem privado, o que se observa é que a oferta de cursos e os seus conteúdos são crescentemente subordinados ao jogo de mercado. Nessa perspectiva Brown e Carasso (2013), em seu estudo, constatam que, face à nova realidade, o ensino se torna pouco prestigiado em razão do valor intrínseco do conhecimento, sendo, sim, estimado em razão do valor instrumental de determinada formação ou diploma. Com isso se fortalece um ambiente de valorização da educação superior "por seu valor 'de troca' (especialmente no mercado de trabalho) ao invés de seu valor 'de uso' (para o estudante)" (BROWN; CARASSO, 2013, p. 149).

Diante dessa realidade, que é própria de um contexto de mercantilização, o presente artigo objetiva analisar a forma como tem sido conduzido o ensino no âmbito da educação superior. Isto é, como o novo cenário afeta o ensino, desde o ponto de vista da gestão? Quais as perspectivas e valores orientam a condução do ensino num contexto de tensionamento privado na educação superior?

Para este estudo, tem-se como foco o caso das universidades comunitárias regionais, que conformam um modelo público não-estatal existente no Brasil desde a segunda metade do século passado, especialmente nos estados do Rio Grande do Sul e Santa Catarina. A opção pelo estudo do modelo comunitário se dá em razão de que são instituições híbridas, que carregam um misto de caraterísticas do modelo estatal e do modelo mercantil, o que facilita que os achados da pesquisa tenham maior possibilidade de transferência para os demais modelos institucionais.

Metodologicamente, o artigo tem por base uma pesquisa de caráter qualitativo realizada entre 2016 e 2017 junto a uma amostragem de quatro universidades comunitárias regionais do estado do Rio Grande do Sul (de um total de oito universidades à época), escolhidas a partir dos critérios (i) porte da instituição e (ii) tempo de existência da IES como universidade, conforme indicado na Tabela 1. Quanto ao primeiro critério, foram consideradas de menor porte as universidades com até doze mil alunos na graduação e menos de dez 
Programas de Pós-Graduação stricto sensu, já as universidades que possuíam de doze a trinta mil alunos na graduação e mais de dez Programas de Pós-Graduação stricto sensu foram classificadas como de maior porte. Para tanto, considerou-se as informações fornecidas pelos sites da IES em 2015 e pelo Censo da Educação Superior de 2013. No que diz respeito ao segundo critério, tomou-se como referência o ano de reconhecimento como universidade, anterior ou posterior a 1990. Diante disso, a amostragem foi constituída por duas universidades de menor porte e duas de maior porte, sendo que duas delas foram reconhecidas como universidade antes de 1990 e as outras duas após 1990.

\section{Tabela 1 - Perfil das universidades comunitárias regionais que compõem o universo da pesquisa, conforme critérios de inclusão na amostra.}

\begin{tabular}{|c|c|c|c|c|}
\hline \multirow{2}{*}{$\begin{array}{c}\text { Universidade } \\
\text { comunitária } \\
\text { regional }\end{array}$} & \multicolumn{2}{|c|}{ Critério porte da IES } & \multicolumn{2}{c|}{$\begin{array}{c}\text { Critério tempo de existência como } \\
\text { universidade }\end{array}$} \\
\cline { 2 - 5 } & Menor porte & Maior porte & $\begin{array}{c}\text { Reconhecimento } \\
\text { anterior a 1990 }\end{array}$ & $\begin{array}{c}\text { Reconhecimento } \\
\text { posterior a 1990 }\end{array}$ \\
\hline Universidade 1 & $\mathrm{X}$ & & $\mathrm{X}$ & \\
\hline Universidade 2 & $\mathrm{X}$ & & & $\mathrm{X}$ \\
\hline Universidade 3 & $\mathrm{X}$ & & $\mathrm{X}$ & \\
\hline Universidade 4 & $\mathrm{X}$ & & & $\mathrm{X}$ \\
\hline Universidade 5 & & $\mathrm{X}$ & & $\mathrm{X}$ \\
\hline Universidade 6 & & $\mathrm{X}$ & & $\mathrm{X}$ \\
\hline Universidade 7 & & $\mathrm{X}$ & $\mathrm{X}$ & \\
\hline Universidade 8 & & $\mathrm{X}$ & $\mathrm{X}$ & \\
\hline
\end{tabular}

Fonte: Sistematização do autor.

A observação, por sua vez, se deu com base em dados primários e secundários. Os dados primários foram coletados por meio de entrevistas semiestruturadas com sujeitos que, em seu cotidiano, se ocupam de pensar e gerir o modelo comunitário de universidade. Deste modo, as entrevistas foram aplicadas junto a três sujeitos de cada instituição, sendo dois professores gestores e um professor não gestor. Quanto aos critérios para a escolha dos dois gestores entrevistados em cada IES, definiu-se que ambos deveriam possuir vivência significativa no campo da gestão institucional; um deles deveria necessariamente fazer parte da administração central da instituição (sendo Reitor, Vice ou Próreitor) e o outro, por sua vez, poderia também ocupar cargo na administração central ou, então, exercer a função de Diretor (de Departamento ou Unidade Acadêmica) ou de Coordenador de Curso. E para a definição do professor não gestor foi considerada a trajetória do mesmo em pesquisas sobre a temática 
da universidade comunitária. No que diz respeito ao universo composto pelos professores com os perfis indicados, registra-se que há, em cada IES pesquisada, aproximadamente cinco professores que ocupam cargos na gestão central, bem uma média de setenta professores ocupando os outros cargos de gestão apontados nos critérios. Da mesma forma, há de um a três professores pesquisadores em cada IES com trajetória intelectual amplamente reconhecida no tema da universidade comunitária. Sendo uma pesquisa qualitativa, a definição da amostra com três sujeitos de cada instituição (dois gestores e um pesquisador), totalizando doze entrevistados, foi definida por ter sido ser considerada capaz de propiciar tanto a complementaridade, quanto a reincidência das informações.

Os dados secundários tiveram como base os Projetos Pedagógicos Institucionais (PPIs) das quatro universidades. O método de análise dos dados resultou de uma construção referenciada na análise de práticas discursivas, conforme proposição de Spink e Medrado (2000), que definem práticas discursivas como "linguagem em ação".

O artigo está estruturado em quatro partes, além desta introdução. A primeira delas apresenta o referencial teórico do capitalismo acadêmico na nova economia, proposto por Slaughter e Rhoades, que dá sustentação a este artigo. Em seguida, aborda-se o modelo comunitário regional em suas características principais, discutindo-se o cenário no qual as instituições comunitárias de educação superior estão inseridas contemporaneamente. No terceiro momento são apresentados os dados coletados por meio da pesquisa, bem como a respectivas análises, que, com base nas questões norteadoras acima apontadas, estão organizados em dois eixos: os valores subjacentes ao ensino e os critérios para definição dos cursos ofertados. Por fim são apresentadas as conclusões, que trazem sínteses conclusivas a respeito da pesquisa, indicando também alguns desafios a serem enfrentados no âmbito da gestão do ensino face a uma realidade de capitalismo acadêmico.

\section{O CONTEXTO DO CAPITALISMO ACADÊMICO NA NOVA ECONOMIA}

O conceito de "capitalismo acadêmico na nova economia", trabalhado por Slaughter e Rhoades (2004), é oportuno para compreender o cenário que se configura no campo da educação superior na contemporaneidade. Os autores identificam que, no transcurso de uma economia industrial para uma economia assentada no conhecimento, as instituições de educação superior passam a desempenhar papel preponderante e as fronteiras entre universidade, mercado e Estado tornam-se menos nítidas. As universidades, nesse contexto, vivenciam o deslocamento de um regime de conhecimento/aprendizagem do bem público - 
caracterizado pela valorização do conhecimento como um bem público, associado às demandas da cidadania, e predominante nas universidades antes das mudanças ocorridas na sociedade no contexto da economia do conhecimento - para um regime de conhecimento/aprendizagem do capitalismo acadêmico, o que está associado a uma lógica econômica na qual o conhecimento é matéria-prima.

O regime do capitalismo acadêmico requer universidades comprometidas nos comportamentos de mercado. Isto está associado, porém, a um contexto maior - que é vinculado à lógica da economia do conhecimento - e diz respeito, inclusive, a medidas adotadas pelo Estado de modo a abrir caminho, isto é, forjar o clima político para o capitalismo acadêmico. Assim, estudando o caso norteamericano, os autores constataram que legislações e políticas mais amplas adotadas no país criaram oportunidades para decisões identificadas com o capitalismo acadêmico no espaço específico das instituições de educação superior. Como exemplo disso, destacam a emergência de um processo de diversificação das fontes de financiamento por parte das IES, o qual decorre diretamente de alterações nas políticas de financiamento estatal às universidades. Ou seja, o financiamento da educação superior norteamericana, antes mais dependente de recursos estatais a pesquisa básica, por exemplo, era tradicionalmente desenvolvida por meio de fundos federais -, em meio a episódios de escassez de verbas foi crescentemente sendo passado para a responsabilidade das instituições, agora provocadas a ampliar suas próprias fontes de receita, seja através de parcerias com empresas para a realização de pesquisas, seja por meio de cursos e atividades ofertados aos estudantes, com o concomitante acréscimo nos valores que lhes serão cobrados ${ }^{1}$ (SLAUGHTER; RHOADES, 2004).

Com a retração do investimento estatal, o pagamento de taxas por parte dos alunos passou a ocupar lugar preponderante para a sustentabilidade das universidades, gerando um comportamento de consumidor por parte dos estudantes (ou seus pais), o que incide sobre suas expectativas quanto aos retornos da educação superior. Passando de aprendizes a consumidores, "o que eles esperam de sua experiência educacional em termos de retornos no investimento em seu "capital humano"' passa a ser uma questão central a ser correspondida pelas IES (SLAUGHTER; RHOADES, 2004, p. 12-13).

Cabe registrar que, diferentemente do Brasil, nos Estados Unidos todas as instituições de ensino superior são pagas, tanto as públicas quanto as privadas. $\mathrm{O}$ custo das primeiras é significativamente mais baixo que o das privadas, devido ao fato de receberem maior repasse de recursos públicos. Mas caso o aluno seja proveniente de outro estado, o valor a ser desembolsado em uma instituição pública é quase igual àquele cobrado nas privadas (VONBUN; MENDONÇA, 2012). 
$\mathrm{O}$ mesmo ocorreu com as mudanças relativas à propriedade intelectual nas universidades norte-americanas ${ }^{2}$, mudanças essas correlacionadas a políticas adotadas em nível nacional (SLAUGHTER; RHOADES, 2004). E isso deve ser entendido como um continum dentro de um mesmo processo de reorganização das instituições adentrando a lógica do capitalismo acadêmico. Assim, segundo os autores, "da mesma forma que as agências de administração de matrículas foram desenvolvidas para fazer da competição por estudantes mais eficiente e bem-sucedida, as agências de transferência de tecnologia e de licenças foram desenvolvidas para explorar a propriedade intelectual" (SLAUGHTER; RHOADES, 2004, p. 68).

Os autores analisam, também, o próprio estilo de gestão que passa a ser desejado nas instituições de educação superior, qual seja, um estilo corporativo que deve perseguir a aproximação com o mundo empresarial, o barateamento de cursos e o aumento do lucro. Nesse contexto, as decisões sobre os currículos e sobre os novos programas ofertados são cada vez mais dependentes de considerações de mercado (RHOADES; SLAUGHTER, 2009). Quando as universidades adequam seus programas de formação à nova economia, a universidade passa a ter como foco "a preparação de estudantes para a empregabilidade na nova economia" (SLAUGHTER; RHOADES, 2004, p. 333).

Rhoades e Slaughter (2009) observam, ainda, uma tendência de alteração na estrutura de empregos nas universidades, em que se destaca a falta de proteção profissional e a não participação nas decisões de cunho acadêmico. Verificam, também, o crescimento de profissionais não docentes, identificados como profissionais de gestão. Sobre os docentes e pesquisadores, especificamente, argumentam os autores que "talvez a maior ameaça colocada pelo capitalismo acadêmico, na nova economia, seja o estar a tornar-se parte do modo como falamos e nos definimos a nós próprios" (RHOADES E SLAUGHTER, 2009, p. 32-33). Não se trata, portanto, apenas de uma questão relacionada à gestão das IES, há "também muitos membros das faculdades se inserem de forma cúmplice no processo de comercialização” (SLAUGHTER; RHOADES, 2009, p. 35).

Porém, conforme o estudo desenvolvido por Slaughter e Rhoades (2004), que teve por base a realidade norteamericana, não é possível afirmar que o regime do capitalismo acadêmico se tornou uma realidade definitiva no campo

2 Segundo os autores, "tradicionalmente, era típico dos professores acadêmicos fazer suas próprias ligações, a fim de poderem controlar o uso comercial dos seus produtos educacionais com direitos de autor [...]. Sob um regime capitalista acadêmico, as políticas institucionais são criadas de forma a dar aos institutos e universidades, em vez de aos seus autores, propriedade intelectual e royalties relativos aos produtos intelectuais das faculdades e dos seus empregados. A nível federal, a legislação tem sido executada de forma a promover os interesses institucionais, em relação ao direito da propriedade intelectual” (RHOADES; SLAUGHTER, 2009, p. 19). 
da educação superior. Ou seja, a ascensão do capitalismo acadêmico não significa a substituição do regime de produção de bens públicos, ao invés disso, ambos “coexistem, se atravessam e se sobrepõem” (2004, p. 29). Nesse sentido, os autores relatam a identificação de estratégias de resistência acionadas por membros e grupos das instituições pesquisadas, de modo que a transição para uma cultura empreendedora, antes de um fato consolidado, é, sim, algo bastante incompleto, assimétrico e inclusive contestado por acadêmicos e também gestores. As razões que justificam resistir são diversas, podendo-se destacar, de modo especial, o compromisso, no âmbito do trabalho acadêmico, com valores do regime de produção do conhecimento dos bens públicos.

Importa destacar, por fim, que o ingresso das universidades no regime do capitalismo acadêmico não diz respeito a um processo de privatização das instituições tradicionalmente sem fins lucrativos (sejam elas estatais ou não). Isto é, essas IES não têm a pretensão de tornarem-se empresas privadas. Distintamente, elas desejam entrar no mercado do setor privado, mas preservando o status de sem fins lucrativos e seus benefícios. "Capitalismo acadêmico não envolve 'privatização'; em vez, ele implica a redefinição do espaço público e da atividade apropriada nesse espaço” (SLAUGHER; RHOADES, 2004, p. 306).

\section{O MODELO COMUNITÁRIO REGIONAL E O CONTEXTO ATUAL DA EDUCAÇÃO SUPERIOR}

As IES comunitárias regionais são de propriedade privada, embora não possuam um dono, sendo mantidas por uma associação ou fundação. Por não possuírem fins lucrativos, qualquer excedente financeiro deve ser reinvestido em educação e, em caso de extinção, o patrimônio deve ser destinado a uma instituição congênere ou pública estatal. A sua base de financiamento é predominantemente oriunda de recursos privados, via pagamento de mensalidades. Sua gestão é colegiada e democrática, contando com a participação da comunidade interna e representantes da comunidade externa em instâncias decisórias (SCHMIDT, 2010; VANUCCHI, 2013). As universidades comunitárias são instituições de vocação regional. Organizadas em estruturas multicampi, são comprometidas com o desenvolvimento social, econômico e cultural das comunidades regionais nas quais estão inseridas (LONGHI, 1998). O modelo comunitário regional é formado por instituições de caráter laico, que se diferenciam das IES comunitárias confessionais em aspectos como a forma de gestão, a participação da comunidade nas instâncias decisórias, o controle e a propriedade do patrimônio e a escolha dos dirigentes (NEVES, 1995; FRANTZ, 2002). 
Em termos legais, as instituições comunitárias estão previstas na Constituição Federal de 1988, em seu artigo 213, com a indicação de que poderão receber recursos públicos (BRASIL, 1988). Há, também, uma lei específica que define e qualifica as instituições comunitárias de educação superior (ICES) - a Lei 12.881, de 2013, chamada "Lei das Comunitárias". Essa lei prevê, por exemplo, que as ICES devem desenvolver programas permanentes de extensão e ação comunitária para formação e desenvolvimento dos estudantes e da sociedade; que elas contam com a prerrogativa de acessar editais governamentais de fomento direcionados às instituições públicas e que podem ser alternativa na oferta de serviços públicos nos casos que não são atendidos por entidades estatais (BRASIL, 2013).

Observa-se, diante do exposto, que as universidades comunitárias, em suas qualidades centrais, apresentam um misto de características públicas e privadas, mas não são nem estatais, nem empresariais - o que permite identificalas como instituições híbridas.

Até o final do século passado, o modelo comunitário figurava como o principal responsável pela interiorização da educação superior nos estados do Rio Grande do Sul e Santa Catarina. Porém, o contexto passou a se transformar profundamente a partir dos anos 2000 e estudos posteriores realizados sobre a realidade das universidades comunitárias evidenciam um conjunto de novos tensionamentos vivenciado por essas IES, como apontam Morosini e Franco (2006), Schmidt (2014), Bertolin e Dalmolin (2014) e Fioreze e McCowan (2018).

Ou seja, desde a virada para o século XXI, quando, no processo de globalização das sociedades e das economias, o Brasil passou a adotar novas políticas no sentido de impulsionar a ampliação do acesso ao nível superior, o contexto nacional começou a se alterar significativamente. Incentivos para a expansão passaram a fazer parte da agenda política brasileira, o que se deu tanto por meio da criação de vagas e instalação de novas IES federais (algumas delas em regiões de abrangência de universidades comunitárias), mas principalmente pela expansão via setor privado mercantil. Como resultado, a quantidade de estudantes na educação superior cresceu aproximadamente quatro vezes em 20 anos (BRASIL/INEP, 2016).

O setor privado foi o que mais cresceu neste período, com ampliação de mais de 350\% nas matrículas entre 1995 e 2012 (KOPPE, 2014). Mas, dentro desse setor, as IES mercantis (as particulares) foram o grande destaque. Entre 1999 e 2009, as matrículas nas IES particulares cresceram mais de $800 \%$ no Rio Grande do Sul, ao passo que nas confessionais, filantrópicas e comunitárias o crescimento foi menor que 50\% (KOPPE, 2014). Verifica-se, assim, a expansão do setor privado mercantil, paralelamente ao encolhimento relativo do campo privado sem fins 
lucrativos (confessionais, filantrópicas e comunitárias). Observando esta realidade com mais detalhamento, nota-se que as IES mercantis investiram pesadamente na oferta de educação a distância e, com isso, alcançaram uma parcela importante de estudantes que, por motivos financeiros ou de tempo, não se enquadravam nas ofertas convencionais das IES tradicionais, como as confessionais e comunitárias. Somado a isso, cabe destacar que instituições mercantis, caracterizadas por estruturas de gestão mais enxutas e verticalizadas, pelo direcionamento das atividades ao ensino de graduação, pela contratação de professores horistas e pela oferta de cursos que geram retorno financeiro, se inseriram no mercado da educação superior com o atrativo das baixas mensalidades, se comparadas com as mensalidades cobradas pelas universidades comunitárias. Essas, além do tripé ensino, pesquisa e extensão, foram se constituindo historicamente por meio de grandes infraestruturas, da contratação de quantidade significativa de professores em regime de tempo integral ou parcial, do investimento em cursos, projetos e pesquisas não rentáveis e, ainda, por estruturas colegiadas de gestão, o que faz delas instituições mais complexas e caras.

Cabe dizer, ainda, que o fenômeno do crescimento do setor privado mercantil, não só no Rio Grande do Sul, mas em todo o Brasil, faz parte de um processo mais amplo e arrojado de mercantilização da educação superior, em que é possível acompanhar, por exemplo, a compra de IES menores por grandes grupos educacionais e, também, a abertura do capital desses grupos na bolsa de valores, como evidencia Sampaio (2014).

Considerando esse contexto, Morosini e Franco (2006) apontam que a nova realidade gera tensionamentos no modelo institucional comunitário, em razão de sua dupla natureza: "o caráter público não-estatal, de serviço à comunidade e o caráter de sua inserção no mundo competitivo e em luta pela sobrevivência" (2006, p. 67). Já Schmidt (2014) mostra que, para sobreviver, IES tradicionais como as comunitárias são pressionadas a mudar o seu estilo de gestão, adotando "práticas consideradas 'de mercado' visando o aumento de receitas e o enxugamento de custos. Competição tornou-se um mote central na gestão de instituições antes despreocupadas quanto à necessidade de garantir um lugar ao sol" (2014, p. 24).

Depreende-se, com isso, que o modelo comunitário está submetido a tensionamentos mercantis que desestabilizam as instituições. Visando sobrevivência, passam a adotar comportamentos de mercado de forma mais intensa e o ensino, por conseguinte, não fica imune de transformações. 


\section{OS CAMINHOS DO ENSINO FACE À REALIDADE DO CAPITALISMO ACADÊMICO}

Ante um contexto de mercantilização marcado pelo capitalismo acadêmico, é pertinente que se analise como tem sido conduzido o ensino no modelo comunitário regional. Para tanto, as fontes de dados que subsidiam a realização das análises a seguir constituíram-se em documentos (PPIs) e entrevistas com gestores e pesquisadores que estudam o modelo comunitário. Os dados foram agrupados e analisados a partir de dois eixos, associados entre si. O primeiro deles diz respeito aos valores subjacentes à condução do ensino e o segundo eixo concerne às definições relativas aos cursos ofertados.

\section{EIXO 1: OS VALORES SUBJACENTES AO ENSINO}

Ao analisar os valores subjacentes à condução do ensino, é possível tomar como referência a compreensão de Nussbaum (2010) de que a constituição de cidadãos aptos a viver em uma sociedade democrática requer o investimento em uma formação de caráter humanista, mais ampla que um ensino pautado na dimensão da técnica profissional e direcionado ao êxito no mercado de trabalho, em que pese o reconhecimento da relevância de tal dimensão. Porém, no contexto atual, conforme exposto, legitima-se uma concepção de formação na qual o ensino não é estimado em razão do valor intrínseco do conhecimento, mas, sim, em razão do valor instrumental de determinada formação ou diploma, como já dito.

O exame dos PPIs das universidades pesquisadas - os quais expressam o conjunto de valores que fundamentam os currículos, garantindo a unidade que deverá resultar em uma identidade institucional comum no que diz respeito ao perfilamento dos egressos - demonstra que todas elas manifestam, como intenção, uma proposta de ensino de caráter humanista, orientada para o bem público. Os trechos que seguem exemplificam essa intencionalidade:

Busca-se, assim, na instituição uma formação humanista, crítica e reflexiva que preconiza a formação de um cidadão emancipado e competente capaz de contribuir para a construção de uma sociedade justa (PPI da Universidade C).

Há necessidade de um trabalho conjunto que tenha como referência um perfil de egresso comprometido com a atuação ética, com respeito ao outro; capacidade de discernimento, criticidade, participação, criatividade com a sociedade e com suas necessidades de transformação (PPI da Universidade D). 
O exame dos documentos permite afirmar que todos eles se alinham com uma ideia de formação para o bem público, na medida em que manifestam a intenção de promover processos formativos pautados por valores e ideiaschave como os que seguem: "atuação ética", "respeito ao outro", "capacidade de discernimento", "transformação", "melhoria direta das condições de vida da sociedade", "promoção da dignidade humana", "erradicação da discriminação, da dominação e do desrespeito à vida humana", "emancipação", "formação crítica e reflexiva" e "contribuição para a construção de uma sociedade justa".

De outro lado, soma-se a esse discurso oficial de caráter humanista, a retórica da inovação e do empreendedorismo. Nesse sentido, todos os PPIs fazem menção à ideia de formação para o desenvolvimento das capacidades de empreendedorismo e de inovação dos estudantes, embora isto apareça apenas pontualmente. Os trechos abaixo demonstram essa preocupação:

A ação acadêmica contemplará desafios que ensejem o despertar do espírito inovador e empreendedor do estudante [...] (PPI da Universidade A).

[A Universidade] busca formar cidadãos conscientes de seu papel na sociedade, capazes de, por seus conhecimentos técnico-científicos, e por seus valores éticos, morais e culturais, construírem novas bases para a sociedade do século XXI, mais voltada para os valores humanos, de maneira inovativa e empreendedora. Inovar e empreender no sentido de produzir novas ideias, novos conceitos, novas metodologias nas diferentes áreas de atuação humana que carreguem a historicidade da humanidade, mas possam ser vanguarda de novas ideias e padrões anteriores (PPI da Universidade B).

Apesar de esta proposta aparecer apenas pontualmente dentro dos quatro PPIs, a sua menção como comportamento que deve ser estimulado nos estudantes pode ser analisada à luz da problematização de Slaughter e Rhoades (2004) a respeito da preocupação assumida pelas IES de preparar seus estudantes para a nova economia. Pois, conforme expresso em um dos PPIs estudados, “[...] o mundo do trabalho se orienta mais para o livre empreendedorismo do que para a preparação para o emprego" (PPI da Universidade A).

Isso posto, pode-se concluir, pela análise dos PPIs, que as universidades comunitárias apresentam um projeto assentado em valores que denotam uma compreensão de ensino pautada em uma proposta de formação humanística, compromissada com o bem público, na qual a formação técnica adequada é articulada com a formação de dimensão cidadã. Ao mesmo tempo, observa-se também, mesmo que de modo menos consistente e constante, a preocupação com um ensino que prepare os egressos para o êxito na chamada nova economia. 
Todavia, o exame das entrevistas realizadas demonstra uma realidade mais complexa. Isto é, os discursos dos sujeitos permitem identificar que, embora se sustente, como ideal subjacente ao ensino, a compreensão de que cabe à instituição universidade promover uma formação atenta para a dimensão da cidadania - onde as humanidades são entendidas como essenciais e as dimensões da técnica e da cidadania devem se harmonizar -, no momento em que os entrevistados aprofundam a reflexão sobre o cotidiano do ensino, algumas contradições emergem de forma recorrente.

Nesse sentido, cabe mencionar que parte significativa dos discursos converge em torno do reconhecimento de uma realidade demarcada pela pressão para que as IES se desloquem em direção à lógica do capitalismo acadêmico, para o estabelecimento de uma relação de clientela com os estudantes. Isso é exemplificado nas falas que seguem:

Nós começamos a dar bastante importância à percepção dos alunos acerca da qualidade do nosso trabalho, enfim, os processos de avaliação foram reforçados e nem sempre, digamos assim, olhar, levar em conta o olhar do aluno, é o melhor em todos os momentos para o saber que vai se desenvolver em uma universidade. [...], porque se ele te diz algumas coisas e você não leva em conta, daqui a pouco ele vai para a concorrência que talvez lhe dê uma resposta mais satisfatória (Pesquisador 2).

Nós hoje talvez estejamos mais preocupados em formar profissionais mais aptos ao exercício de uma atividade profissional, quase que numa resposta imediata à formação de um ganho financeiro, ganho econômico, do que propriamente uma formação de formar, por exemplo líderes, de formar um conjunto de pessoas intelectualmente preparadas para enfrentar desafios futuros (Gestor 5).

Também se observa, nos depoimentos, o quanto a realidade institucional é afetada por uma cultura que se ergue em torno da ideia de educação superior como bem privado, a qual toma conta das mentalidades e do senso comum partilhado pelos estudantes no que tange a suas expectativas com relação à universidade, como se observa nas falas que seguem:

A Universidade $\mathrm{Y}$ tem como uma de suas missões a formação de cidadãos íntegros, conscientes de seu papel na sociedade, além da especialização técnica. [...] Existem alunos que não valorizam estas informações, uma vez que estão "pagando especificamente" pelo conteúdo que está no plano da disciplina (Gestor 4).

[...] o aluno entra, por exemplo, no curso de Direito, e quer fazer disciplinas de Direito, se tiver uma disciplina de Sociologia, de Psicologia, ele já está reclamando, porque ele não veio lá para estudar isso, ele veio para estudar Direito. Então o próprio aluno traz uma ideia inadequada de universidade (Pesquisador 4). 
Outra face deste tensionamento de ordem cultural diz respeito ao próprio corpo docente. Nesse sentido, o perfil dos professores - que nem sempre partilham do ideal proposto no PPI - torna-se um limitador para a efetivação do projeto pedagógico institucional em toda a sua completude, realidade que é reforçada por uma certa omissão da gestão, ou mesmo pela desconsideração, da parte de gestores, com relação ao que está previsto no PPI. As falas na sequência exemplificam tal compreensão.

Então, eu acho que é mais ou menos geral a ideia de que os professores se dedicam simplesmente a dar suas aulas, nem sempre pensando na natureza da própria instituição. Agora, essa é uma questão que teria que ser aprofundada, porque eles são reféns de uma mentalidade, acho que cabe aos gestores propor iniciativas nesse sentido de quebrar esse círculo vicioso [...] (Pesquisador 4).

[...] ainda falta sintonia, muita sintonia entre nós, não acho que isso seja claro para todos os gestores. Gestores, professores, em um modo geral, mas eu chamo a responsabilidade para nós, mesmo o gestor que seja coordenador lá do curso, bom, qual é a nossa direção? (Gestor 6).

Os dados permitem que se recorra à reflexão de Slaughter e Rhoades (2004) de que, no regime do capitalismo acadêmico, legitima-se o conceito de que a relação entre universidade e estudante é de compra e venda de um bem, estabelecendo-se o comércio dos diplomas, sem a devida preocupação com o real aprendizado. O estudante, nessa lógica, se comporta como um consumidor preocupado com o valor que será agregado ao seu capital humano. Por outro lado, a visão de educação superior partilhada por parcela dos professores - e que de certa forma é referendada pelos gestores -, também indica o engajamento desses sujeitos nos comportamentos de mercado, contribuindo para o avanço do capitalismo acadêmico.

\section{EIXO 2: OS CRITÉRIOS PARA DEFINIÇÃO DOS CURSOS OFERTADOS}

O segundo foco consiste no olhar sobre as carreiras ofertadas pelas instituições por meio do ensino de graduação. Busca-se, assim, identificar os princípios que orientam as decisões sobre abertura, fechamento e manutenção de cursos, isto é, em que medida as decisões da gestão privilegiam as carreiras financeiramente rentáveis para as instituições ou, de forma distinta, até que ponto se decide por formar profissionais em carreiras que, mesmo não gerando 
rentabilidade financeira para a IES, são consideradas socialmente relevantes devido às externalidades positivas que produzem, como é o caso dos cursos de formação de professores, por exemplo.

De antemão, é possível afirmar que a análise dos discursos institucionais permite identificar que há, como tendência geral no modelo comunitário, um tensionamento na direção da redução ou, no mínimo, da precarização na oferta de cursos que não geram retorno, o que acontece em nome da sustentabilidade financeira num contexto que impele para cortes de gastos. Nesse sentido, são recorrentes depoimentos do tipo "nós já tivemos bem mais cursos de licenciaturas" (Gestor 1) ou, também,

Nosso curso de Filosofia não tem oferta nos últimos anos, o curso de Sociologia, Ciências Sociais, ele deixou de ter demanda, não conseguimos criar cursos de Artes, nas áreas de artes nós não temos nenhum curso nessas áreas, e vários cursos de licenciatura também, nós temos dificuldades de manter (Pesquisador 2).

Contudo, em que pese tal tendência, se observa também que, na tensão entre o ideal e o real, é recorrente nos discursos a manifestação de um desejo institucional pela manutenção de cursos considerados socialmente necessários, mas que geram prejuízo financeiro à IES. Esse é o caso emblemático dos cursos de licenciatura, os quais vêm, ao longo das últimas décadas, sofrendo com a chamada crise da profissão docente. Como mostra Diniz-Pereira (2011), trata-se de um descrédito associado a fatores como a baixa expectativa de renda na profissão, a queda do status social da docência e a existência de um sentimento de inferioridade e incapacidade, o que é fortalecido e perpetuado pelas próprias políticas educacionais. Embora cientes da existência desse cenário de fragilidade, os entrevistados reiteram sua preocupação com a manutenção de tais cursos e justificam isso na própria missão da universidade comunitária, instituição originariamente erguida sob a égide do compromisso social com o desenvolvimento regional. Os depoimentos que seguem são exemplares de tal postura:

Mesmo assim, a gente entende que tem um número, um conjunto de ofertas, que mesmo que com uma demanda extremamente fragilizada nós iremos manter igual. Isso se aplica, por exemplo, na formação de professores. Nós temos, assim, cursos de formação de professores que não são cursos superavitários, mas que são cursos que são, assim, de posicionamento institucional, de cumprimento da nossa missão, a gente mantém mesmo assim, o que não dá é para manter tudo (Gestor 1).

Nós, independente do resultado financeiro, nós temos a política de manter as Licenciaturas. Temos treze licenciaturas, financeiramente elas dão prejuízo, mas nós estamos buscando alternativas sob o ponto de vista da estrutura da 
reorganização curricular [...]. Agora, financeiramente não tem resultado. Bom, mas eles dão resultado no todo. No todo em que sentido? No todo enquanto ideal de universidade. Se eu fechar todas as licenciaturas eu digo assim, "mas que universidade é essa?” (Gestor 7).

A instituição é permeável ao contexto socioeconômico da região onde está inserida e, consoante os cenários, é afetada pela redução de matrículas, pela inadimplência, pela evasão dos alunos. Ao mesmo tempo, a instituição investe nas demandas da região de sua abrangência, mesmo que determinados cursos ou ações não demonstrem equilíbrio financeiro, como é o caso das licenciaturas, por exemplo (Gestor 8).

[...] quem são os cursos deficitários? Aí são justamente os das humanas. Teoricamente são as áreas que ajudariam a problematizar, trazer problemas para a sociedade e ajudar a sociedade, os profissionais, a pensarem sobre o conjunto de questões que, se não tivesse esses cursos, se não tivesse a presença de professores desses cursos dentro do ambiente universitário, nós certamente iríamos seguir tendencialmente numa direção tecnicista, mais economicista, e deixaríamos de ter no interior da instituição, da universidade, da ideia de universidade, aquilo que é próprio dela, que é esse tensionamento de ideias, de concepções, de projetos. Então acho que [investir nos cursos deficitários] é fundamental, é uma decisão acertada nesse sentido (Pesquisador 3).

Observa-se, nessa linha, que parte significativa dos entrevistados manifesta que a gestão institucional tem adotado alternativas no sentido de manter cursos que, apesar de deficitários, são entendidos como necessários para o "ideal de universidade" - usando a expressão do entrevistado acima. Olhando com mais detalhamento para isso verificam-se, por exemplo, medidas para aquecer a demanda, como mencionado pelo Pesquisador 3: "nós já mantemos gratuidade [de 50\%] paras licenciaturas há um bom tempo", o que "quem deveria fazer é o governo, não é?... mas onde o governo não cobre há uma decisão institucional clara".

Vê-se, também, a realização de adaptações curriculares, como o compartilhamento de disciplinas e o agrupamento de turmas, as quais visam reduzir custos e, assim, ampliar a possibilidade de oferta dos cursos sem redundar em maior prejuízo financeiro. O depoimento na sequência denota a adoção desse tipo de solução:

As coordenações, os colegiados desses cursos são solicitados que eles adaptem, na medida do possível, o compartilhamento de disciplinas, para que então os cursos possam permanecer. Então, nós já tivemos cursos que estavam praticamente extintos há alguns anos e as direções e coordenações trabalharam e procuraram uma integralização maior, de modo que eles conseguiram se recuperar, mesmo que os seus estudantes façam a maior parte das disciplinas em outros cursos (Gestor 3). 
Essas adaptações, contudo, podem resultar em precarização, como argumenta um entrevistado a respeito dos agrupamentos realizados em virtude das condições financeiras: “[...] todos nós sabemos que o desejável não é ter sessenta alunos em sala de aula, mas a concorrência te leva a tentar maximizar, digamos, o rendimento, em disciplinas que assim permitem [...]" (Pesquisador 2). Assim, embora existam resistências no sentido da preservação da oferta de cursos entendidos como relevantes para um ideal de universidade, como observado, a precarização do ensino acaba sendo uma contingência.

É inegável que, até certo ponto, as decisões de gestão no que tange aos rumos do ensino submetem-se à lógica de mercado. E isso está associado, em grande medida, à inexistência de um posicionamento do Estado por meio de políticas públicas capazes de impulsionar de fato a formação em carreiras que podem ser consideradas necessárias para a constituição do bem público - como as licenciaturas e as humanidades, áreas que, como mencionado na entrevista, garantem a reflexão dentro da universidade, preservando o próprio sentido de universidade. Nesta perspectiva, na atual configuração da educação superior brasileira, as instituições do setor privado, sejam elas com ou sem fins lucrativos, estão submetidas à regulação de mercado, do que resulta que a definição das carreiras e áreas a serem oferecidas está afeita à lógica da concorrência por alunos-clientes. Assim, como consequência desse cenário, o interesse dos futuros consumidores em potencial é um critério que pesa na definição dos cursos que serão disponibilizados, o que fica evidenciado no depoimento que segue.

Então, inclusive uma previsão de engenharias que nós tínhamos para lá [em um campus fora de sede] a gente deixou de lado porque a gente viu que a situação econômica não favorecia o custo de tais cursos. E aí o que a gente não ia oferecer, e que tem em todos os outros [campi], é Direito, mas basicamente todo mundo quer Direito, então a gente já elaborou um projeto para também elaborar essa oferta para esse campus [...] (Gestor 3).

Princípios de mercado - como o potencial de venda de um curso influenciam nas decisões, embora os dados coletados permitam afirmar que não constituem o único elemento considerado pelas ICES na definição dos cursos a serem ofertados. Nesse sentido, um achado importante da pesquisa é de que não há um fenômeno unívoco na direção de um comportamento absolutamente submetido à lógica do capitalismo acadêmico, mas, sim, configura-se nas instituições um processo tensionado por forças distintas. Nas palavras de um entrevistado, "não dá para manter tudo, mas nós também não vamos manter só cursos que dão dinheiro, nós vamos manter cursos que a gente entende que são aderentes e que contribuam no projeto da instituição" (Gestor 1). 
Ainda a respeito das decisões sobre os cursos a serem ofertados, a pesquisa também permitiu observar que, numa estrutura de gestão colegiada e democrática, como a observada no modelo comunitário, distintos interesses precisam ser considerados. Nesse sentido, um entrevistado menciona que "dentro da nossa estrutura e da forma que nós atuamos", é muito mais fácil abrir do que extinguir um curso (Gestor 3). Na mesma direção tem-se o depoimento que segue, o qual consiste numa reflexão sobre possíveis encaminhamentos a serem tomados com relação a cursos deficitários: "nós precisamos, talvez, ter um posicionamento mais efetivo, não de interferência, não é isso, mas de chamar os colegas e ver como que nós podemos melhorar essa relação deles com a instituição [...]” (Gestor 5).

A dificuldade de implementar decisões mais verticalizadas no sentido do fechamento de cursos, bem como a preocupação com uma postura negociada que não soe como interferência dos gestores maiores, conforme evidenciado nas falas, são traços de um modelo institucional assentado em uma estrutura colegiada de gestão. Modelo no qual opções que privilegiem exclusivamente a oferta de cursos que geram retorno financeiro são difíceis de acontecer, pois ao mesmo tempo em que existe o tensionamento nessa direção, também há, de outro lado, o tensionamento das vozes que, em nome de outros interesses - tais como a preservação de um ideal de universidade -, pressionam para o investimento nos cursos socialmente relevantes, mas nem sempre rentáveis.

\section{CONCLUSÕES}

Por meio da pesquisa desenvolvida e aqui apresentada torna-se possível inferir que há, na educação superior, um movimento de deslocamento do ensino na direção do regime de produção do conhecimento e aprendizagem do capitalismo acadêmico, segundo o qual as IES passam a assumir comportamentos de mercado de forma mais veemente.

Tal deslocamento, para além de mera iniciativa de gestão das IES, decorre de forças mais amplas e complexas, próprias de um contexto em que a educação superior passa a ser compreendida como um bem privado, a ser comprado e vendido numa lógica mercantil. No âmbito do ensino, estabelece-se uma relação de troca entre cliente-estudante e fornecedor-universidade, onde o retorno dos diplomas em termos de ampliação do capital humano dos alunos é a tônica, em detrimento da formação de cidadãos aptos à vida em sociedade. Isto está relacionado a um ethos privatista que perfaz a visão de homem e de mundo que passa a ganhar espaço no senso comum e na própria comunidade acadêmica a respeito do lugar e das funções da educação superior na sociedade. Nesse sentido, 
cabe trazer a ponderação de Rhoades e Slaughter (2009), de que a maior ameaça no contexto do capitalismo acadêmico talvez seja a de que ele tem se incorporado na forma como os sujeitos das universidades se portam e se definem.

Contudo, os dados referentes aos rumos do ensino nas instituições comunitárias aqui pesquisadas também permitem concluir que tal tendência convive com uma postura de resistência na direção da preservação dos valores da educação superior como bem público, os quais são associados com uma perspectiva de formação humana e cidadã. Esta constatação coaduna com a análise de Slaughter e Rhoades (2004) de que resistir constitui-se em uma estratégia possível no fazer cotidiano da universidade e, nesse contexto, o regime do capitalismo acadêmico coexiste com o regime dos bens públicos.

Isso posto percebe-se que há, em termos de ensino, um tensionamento entre ambos os regimes, o que fica patente, também, quando os dados evidenciam que, em nome da necessidade de sobrevivência em um contexto de submissão à regulação de mercado, as universidades são pressionadas a reduzir investimentos em cursos não rentáveis, mesmo quando considerados de relevância social. Porém, isto não significa a extinção de tais cursos ou sua substituição exclusiva por cursos rentáveis, pois existe um tensionamento contrário, originado na preservação de uma concepção de educação superior como bem público. E a perspectiva colegiada de gestão universitária parece ser um ponto fundamental na garantia desse equilíbrio.

Assim, é possível concluir que, se é verdade que a realidade de mercantilização da educação superior, associada ao bem privado, é inexorável e deverá ser considerada na gestão das universidades, é também verdade que a resistência no sentido da preservação da educação superior como espaço de formação de cidadãos com capacidade crítica e reflexiva também é um dado da realidade, claramente observado no campo pesquisado. Esta constatação entra em contradição com as análises mais simplistas de que as universidades, especialmente aquelas de direito privado, sucumbiram e estão completamente subjugadas à lógica mercantil. O cenário mostra-se mais complexo que isso.

Diante do exposto, depreende-se o desafio posto à gestão institucional de garantir o estabelecimento de um equilíbrio entre as duas perspectivas - sob pena de comprometer os grandes valores que subjazem a missão pública da educação superior, como a democracia, o respeito à diferença e à diversidade, a formação de cidadãos e a afirmação da autonomia -, o que perpassa por preocupar-se, na condução do ensino, com a preservação das humanidades, segundo defesa de Nussbaum (2010). E disso depreende-se outro desafio para a gestão, o de refletir permanentemente sobre o seu fazer, o que implica qualificação técnica e teórica, 
garantindo com isso a clareza necessária para conduzir instituições universitárias de modo a respeitá-las enquanto espaços a priori de formação humana - e não de mera comercialização.

\section{REFERÊNCIAS}

BERTOLIN, Julio Cesar Godoy; DALMOLIN, Bernadete Maria. As universidades comunitárias e a emergência de mercados na educação superior: entre a pressão da competição e o diferencial dos valores acadêmicos. Revista Brasileira de Política e Administração da Educação, v. 30, n. 1. p. 139-159, jan./abr. 2014.

BRASIL. Lei $\mathbf{n}^{\mathbf{0}} \mathbf{1 2 . 8 8 1}$, de 12 de novembro de 2013. Dispõe sobre a definição, qualificação, prerrogativas e finalidades das Instituições Comunitárias de Educação Superior - ICES, disciplina o Termo de Parceria e dá outras providências. Poder Executivo, Brasília, 2013.

. Constituição (1988). Constituição da República Federativa do Brasil. Brasília, DF: Senado Federal, 1988.

BRASIL/INEP. Censos da Educação Superior. Disponível em: http://portal. inep.gov.br/web/censo-da-educacao-superior. Acesso em mai. 2016.

BROWN, Roger; CARASSO, Helen. Everything for sale? The marketization of UK higher education. Routledge: London and New York, 2013.

CASTELLS, Manuel. A sociedade em rede. São Paulo: Paz e Terra, 1999.

CASTRO, Alda Maria Duarte Araújo; ARAÚJO, Nataniel da Vera-Cruz Gonçalves. Educação superior no Brasil e a utilização da Educação a Distância como estratégia de expansão e massificação. Revista Brasileira de Política e Administração da Educação - Periódico científico editado pela ANPAE, [S.1.], v. 34, n. 1, p. 189-209, abr. 2018.

DINIZ-PEREIRA, Júlio Emílio. O ovo ou a galinha: a crise da profissão docente e a aparente falta de perspectiva para a educação brasileira. Revista Brasileira de Estudos Pedagógicos, v. 92, n. 230, p. 34-51, jan./abr. 2011. 
FIOREZE, Cristina; MCCOWAN, Tristan. Community universities in the South of Brazil: prospects and challenges of a model of non-state public higher education. Comparative Education, v. 54, n. 3, p. 370-389, 2018.

FRANTZ, Walter. Universidade Comunitária: uma iniciativa pública não-estatal em construção. In: SILVA, Enio Waldir; FRANTZ, Walter. O papel da extensão e a questão das comunitárias. Ijuí: Unijuí, 2002. p. 15-102.

KOPPE, Leonardo Renner. Instituições de Ensino Superior Privadas: organizações de ensino com fins lucrativos no Rio Grande do Sul. 2014. Tese (Doutorado em Sociologia) - Universidade Federal do Rio Grande do Sul, Porto Alegre, 2014.

LONGHI, Solange Maria. A face comunitária da universidade. 1998. Tese (Doutorado em Educação) - Universidade Federal do Rio Grande do Sul, Porto Alegre, 1998.

MOROSINI, Marília; FRANCO, Maria Estela Dal Pai. Universidades Comunitárias e sustentabilidade: desafio em tempos de globalização. Educar em Revista, Curitiba, v. 22, n. 28, p. 55-70, 2006.

NEVES, Clarissa Eckert Baeta. Ensino superior privado no Rio Grande do Sul. Documento de trabalho do Nupes. São Paulo, USP, n.6, 1995.

NUSSBAUM, Martha C. Sin fines de lucro: por qué la democracia necesita de las humanidades. Buenos Aires: Katz, 2010.

RHOADES, Gary; SLAUGHTER, Sheila. O capitalismo acadêmico na nova economia: escolhas e desafios. In: PARASKEVA, João M. (Org.). Capitalismo Acadêmico. Mangualde, Portugal: Edições Pedago, 2009.

SAMPAIO, Helena. Diversidade e diferenciação no ensino superior no Brasil: conceitos para discussão. Revista Brasileira de Ciências Sociais, v. 29, n. 84, p. 43-55, fev. 2014.

SCHMIDT, João Pedro. Mercantilização da educação superior: o campo dos negócios e o papel das IES públicas e comunitárias. Textual/Sinpro, Porto Alegre, v. 2, n.20, p. 22-28, Jun./Nov. 2014. 
. O Comunitário em tempos de público não estatal. Avaliação, Campinas; Sorocaba, SP, v. 15, n. 1, p. 9-40, mar. 2010.

SLAUGHTER, Sheila; RHOADES, Gary. Academic capitalism and the new economy: markets, state and higher education. Baltimore: The Johns Hopkins University Press, 2004.

SPINK, Mary Jane; MEDRADO, Benedito. Produção de sentidos no cotidiano: uma abordagem teórico-metodológica para análise das práticas discursivas. In: SPINK, Mary Jane. Práticas discursivas e produção de sentidos no cotidiano: aproximações teóricas e metodológicas. 2. ed. São Paulo: Cortez, 2000. p. 41-61.

TOLEDO, Luiz Fernando. Só 8 grupos concentram 27,8\% das matrículas do ensino superior. Estadão, 8 jun 2016.

VANUCCHI, Aldo. A universidade comunitária: o que é, como se faz? 4. ed. São Paulo: Loyola, 2013.

VONBUN, Christian; MENDONÇA, João Luís de Oliveira. Educação superior: uma comparação internacional e suas lições para o Brasil. Brasília: IPEA, 2012.

WORLD BANK. The Financing and Management of Higher Education: a status report on worldwide reforms. Washington: World Bank Human Development Group, 1998.

CRISTINA FIOREZE é Doutora em Sociologia pela Universidade Federal do Rio Grande do Sul (2017), com estágio doutoral (PDSE/Capes) no Institute of Education da University College London (Londres/UK). É Mestre em Educação pela Universidade de Passo Fundo (2004) e Bacharel em Serviço Social pela Universidade de Caxias do Sul (2001). É professora da Universidade de Passo Fundo desde 2004. E-mail: fiorezecristina@gmail.com

Recebido em setembro de 2018 Aprovado em novembro de 2018 